\title{
Erratum to: Integrated soil and plant phosphorus management for crop and environment in China. A review
}

\author{
H. Li • G. Huang • Q. Meng • L. Ma • L. Yuan • \\ F. Wang $\cdot$ W. Zhang $\cdot$ Z. Cui $\cdot$ J. Shen $\cdot$ X. Chen $\cdot$ \\ R. Jiang $\cdot$ F. Zhang
}

Published online: 8 June 2013

(C) Springer Science+Business Media Dordrecht 2013

\section{Erratum to: Plant Soil (2011) 349:157-167 DOI 10.1007/s11104-011-0909-5}

The original version of this paper unfortunately contained errors. In Abstract, " $24.7 \mathrm{mg} \mathrm{kg}^{-1}$ " should be " $20.7 \mathrm{mg}$ $\mathrm{kg}^{-1}$ in 2006 ".

The online version of the original article can be found at http:// dx.doi.org/10.1007/s11104-011-0909-5.

H. Li • G. Huang • Q. Meng $\cdot$ L. Ma $\cdot$ L. Yuan $\cdot$ F. Wang

W. Zhang $\cdot$ Z. Cui $\cdot$ J. Shen $\cdot$ X. Chen $\cdot$ R. Jiang $\cdot$

F. Zhang $(\square)$

Department of Plant Nutrition, China Agricultural

University, Key Laboratory of Plant-Soil Interactions,

Ministry of Education, Key Laboratory of Plant Nutrition,

Ministry of Agriculture,

Beijing 100193, Peoples Republic of China

e-mail: zhangfs@cau.edu.cn 